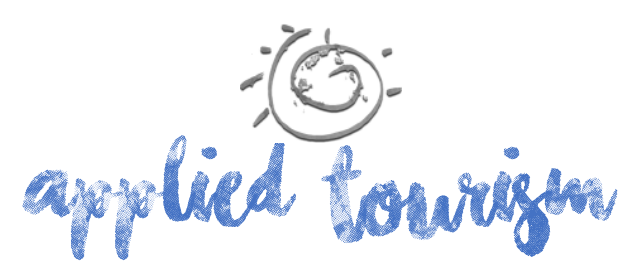

Volume 2, número 2, 2017, p. 161-179

\title{
TURISMO DE NEGÓCIOS E EVENTOS EM BALNEÁRIO CAMBORIÚ-SC: perspectivas de expansão e consolidação frente a implantação do centro de eventos do município
}

\author{
Elisângela da Silva Rocha \\ Doutoranda em Turismo e Hotelaria - Universidade do Vale do Itaja \\ Docente Instituto Federal Catarinense - Campus Camboriú \\ elisangela.rocha@ifc.edu.br \\ Tânia Regina Egert Petry \\ Mestre em Turismo e Hotelaria \\ Universidade do Vale do Itajai \\ taniaegert@edu.univali.br \\ Luciana de Paiva Riciardi \\ Graduada em Tecnologia em Negócios Imobiliários \\ Instituto Federal Catarinense - Campus Camboriú \\ luriciardi@hotmail.com
}

Recebido: 28 de junho, 2017

Aprovado: 01 de agosto, 2017

\section{RESUMO}

O turismo no município de Balneário Camboriú-SC ainda é voltado principalmente para o binômio "Sol e Mar". Entretanto, o segmento de negócios e eventos tem se mostrado estratégico, devido especialmente à capacidade de minimizar os efeitos da sazonalidade e ocorrer independentemente da existência de atrativos naturais ou culturais. Diante disso, o presente estudo se propôs a investigar as perspectivas de representantes do setor turístico, de construção civil e imobiliário sobre a expansão e consolidação desse segmento em Balneário Camboriú tendo em vista a construção do Centro de Eventos no município. A pesquisa foi do tipo exploratóriodescritiva, com abordagem qualitativa. A coleta de dados realizou-se através de um questionário com perguntas fechadas em quatro rodadas de entrevista no mês de outubro/2015. Os resultados evidenciaram que o empreendimento poderá trazer uma nova dinâmica para a cidade com um dos mais modernos e bem equipados espaços para receber eventos de grande porte no Brasil.

Palavras-chaves: Turismo de negócios e eventos. Construção civil. Setor imobiliário. 


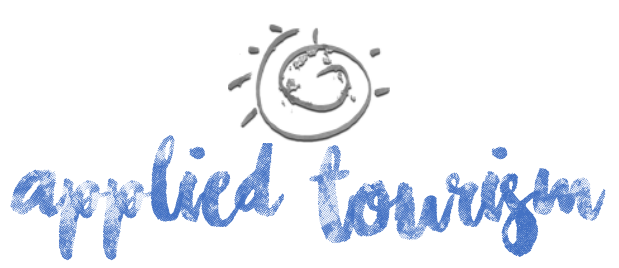

Volume 2, número 2, 2017, p. 161-179

\section{INTRODUÇÃO}

Nos últimos anos o turismo tem se apresentado como uma atividade de grande importância para o desenvolvimento de países e regiões, correspondendo a praticamente 10\% do Produto Interno Bruto (PIB) mundial e pela geração de mais de 276 milhões de empregos, incluindo as atividades diretas, indiretas e induzidas que o setor participa (Wttc, 2015). No Brasil, o turismo é responsável por 9,6\% do PIB nacional, gerando 8,8 milhões de empregos na sua contribuição total (Wttc, 2015b).

No contexto catarinense, verifica-se que o Estado vem demonstrando crescimento desse setor nos últimos anos, principalmente no período da temporada de verão. Segundo dados divulgados pela Abrasel SC (2016), houve aumento no número de turistas em Santa Catarina na temporada 2016 em comparação ao mesmo período de 2015. Com a alta do dólar, cresceu o número de turistas estrangeiros visitando o Estado, sobretudo de argentinos que estão com a economia mais estável, mas também de brasileiros, que optaram por fazer viagens nacionais em detrimento de viagens internacionais.

Dentre os destinos brasileiros mais visitados, figurando em sétimo lugar na procura por turistas estrangeiros (Mtur, 2014) encontra-se Balneário Camboriú, localizada no litoral norte do Estado de Santa Catarina. Com uma população fixa de 128.155 habitantes, 46,23 $\mathrm{km}^{2}$ de área territorial e uma das maiores rendas per capita do país, os principais setores de sua economia são o turismo e a construção civil (Ibge, 2015).

Com a implantação do novo Centro de Eventos no município, além do fluxo turístico de 'sol e mar', que ocorre predominantemente na alta estação, a previsão é de que se verifique um crescimento significativo na captação e realização de negócios e eventos. Esse segmento tem a capacidade de gerar benefícios econômicos e sociais para empreendedores, promotores, comércio local, restaurantes, hotéis, entre outros profissionais direta e indiretamente envolvidos. Com crescimento anual de 


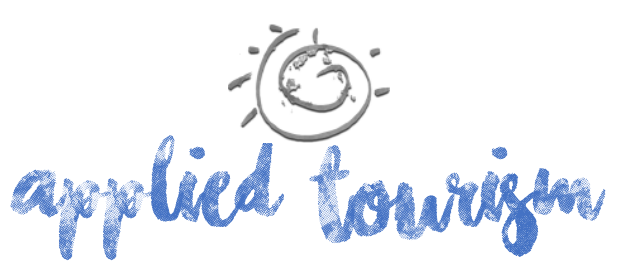

Volume 2, número 2, 2017, p. 161-179

aproximadamente $12 \%$, esse mercado supera o próprio setor do turismo como um todo (Coutinho \& Coutinho, 2007).

O espaço contará com um total de 33.582,54 $\mathrm{m}^{2}$ de área urbanizada e de estacionamento, além do bloco central com salas de conferências, praça de alimentação e acesso ao zoológico do Parque da Santur. O projeto arquitetônico prevê estrutura para vinte e oito salas modulares, com capacidade para até três mil pessoas. Foi desenvolvido com base em princípios de sustentabilidade, incluindo máximo aproveitamento de luz natural, utilização de equipamentos que reduzem o consumo de energia, uso de placas fotovoltaicas, captação de água da chuva, uso de dispositivo para reduzir o consumo de água e maximização da ventilação natural (Sinduscon, 2015).

Diante desta conjuntura, a presente pesquisa se propõe a investigar as perspectivas de representantes do setor turístico, da construção civil e imobiliário de Balneário Camboriú sobre a expansão e consolidação do segmento de negócios e eventos no município, aproveitando o potencial turístico já existente. Com a capacidade de minimizar os efeitos da sazonalidade (Donaire et al., 2009), esse segmento movimenta bilhões de reais no Brasil (Mtur, 2010).

\section{Turismo de Negócios e Eventos}

O Turismo de Negócios corresponde a um conjunto de atividades turísticas derivadas de encontros de interesse profissional, associativo, institucional, podendo ser de categoria comercial, promocional, técnico, científico e social (Canton, 2009; Swarbrooke \& Horner, 2002). Segundo Beni (2001), os eventos criam fluxos turísticos, pois em sua essência também são atrativos turísticos. Devido aos espaços oferecidos e atrações diversificadas que melhor atendem as expectativas dos turistas de negócios, os destinos urbanos são mais procurados para a realização do Turismo de Negócios (Hunt \& Crompton, 2008). 


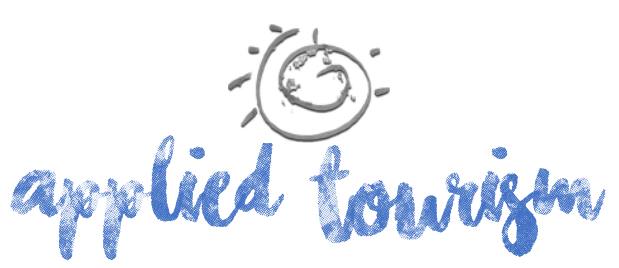

Volume 2, número 2, 2017, p. 161-179

ambientais da região, a partir de ações interligadas ao país e cidades-sedes, tornando os destinos competitivos e mais voltados à sustentabilidade, já que aciona toda a cadeia de atividades relacionadas ao turismo (Getz, 1997; Hoeller, 2002; Batista \& Pinto, 2007; Page, 2009; Allen et al., 2011; Cook et al., 2010; Cooper et al., 2008; Crosdales \& Tomazzoni, 2010).

Com um planejamento adequado para recepção de eventos, as cidades podem melhorar sua imagem e ter um maior fluxo de visitantes (Tyler et al., 2001). Os eventos podem propulsionar retorno para diversos segmentos da comunidade (de Luca Filho, 2014).

Os atores/agentes envolvidos com o turismo de eventos, segundo a Ubrafe - em pesquisa realizada pela Fipe (2013) são os promotores, montadores e infraestrutura, espaços, expositores, visitantes e outros fornecedores (de Luca Filho, 2014).

O processo de busca de eventos por parte dos destinos em geral é realizado pelos Convention \& Visitors Bureau - e se for associado à ICCA encontra facilmente tais dados - que, posteriormente entram em contato com representante da associação (da cidade, do Estado ou do país) para conferir se há interesse da regional (de Luca Filho, p. 146, 2014).

Decorrente da expansão e desenvolvimento do turismo de eventos a nível mundial verificou-se que a realização de eventos em grande escala precisa que seja uma decisão política, devido à necessidade de grandes investimentos na construção e modernização de aeroportos e centros de convenções e também em forma de subsídios financeiros para a iniciativa privada (Britto \& Fontes 2002; Magalhães et al., 2015). Conforme Oliveira (2002) os gestores públicos e privados devem se unir em prol do desenvolvimento do turismo.

A escolha de uma localidade para sediar um evento é influenciada por inúmeras razões como: espaço para eventos, infraestrutura básica - segurança, questões políticas relacionadas com entidades de classe promotoras dos eventos, apoio governamental, 


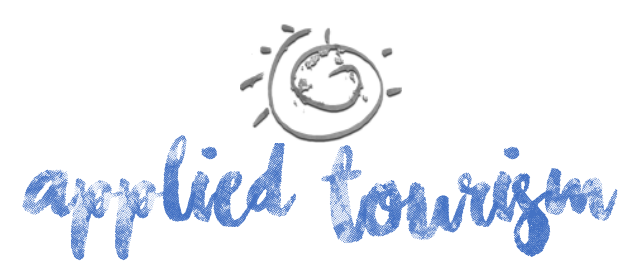

Volume 2, número 2, 2017, p. 161-179

saneamentos, acessos até o destino e no destino, sinalização - preços, imagem da região, características do aglomerado industrial da região, serviços no destino - taxistas, transportes coletivos, hospedagem, alimentação, entretenimento, lazer, atrativos turísticos, custo, patrocínios potenciais na região dentre outros (de Luca Filho, 2014).

A construção do Centro de Eventos em Balneário Camboriú deverá fomentar a atividade em todo o Estado. Com os investimentos da União, Estado, Municípios e empresários, em rodovias, aeroportos, espaços para eventos e na qualificação profissional e em novos hotéis e com a sinergia existente no trade turístico e de eventos e com capacitação na gestão de espaços de eventos e de prestadores de serviços e na captação de eventos e de recursos, a tendência nos próximos anos é de que Santa Catarina e seus empresários e trabalhadores continuem se destacando no cenário nacional de eventos - em especial nas feiras de pequeno e médio porte (de Luca Filho, p. 09-10, 2014).

Balneário Camboriú é considerada um dos maiores pólos turísticos do sul do País, e foi apontado recentemente como o sétimo destino brasileiro mais procurado por turistas estrangeiros de acordo com o Ministério do Turismo - MTur / Fundação Instituto de Pesquisas Econômicas - Fipe (2014). Também conhecida como capital catarinense do turismo e carinhosamente chamada de Maravilha do Atlântico é repleta de atrativos, diversas opções de compras e lazer, ótima rede hoteleira e gastronômica.

Seu litoral é composto por nove praias que agradam todos os gostos. A praia central é palco de inúmeros eventos como Reveillon, Brilhos de Natal e apresentações artísticas e esportivas. Alem de belas praias, Balneário Camboriú tem atrações para todos gostos e idades, a exemplo temos o Cristo Luz, Parque Unipraias, Shopping Centers, ecoturismo, esportes radicais entre outros. 


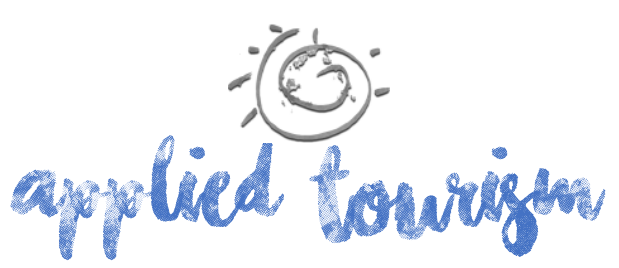

Volume 2, número 2, 2017, p. 161-179

A rede hoteleira conta com aproximadamente cento e quinze estabelecimentos que oferecem cerca de seis mil e oitocentas unidades habitacionais com uma das melhores e maiores ofertas de leitos do País.

O município possui uma população fixa de 128.155 habitantes em apenas $46,23 \mathrm{~km}^{2}$ de área territorial segundo Ibge (2015) e uma das maiores rendas per captas do país com $\mathrm{R} \$$ 14.441,00 tem como principais setores da economia, o Turismo e a Construção Civil, sendo esse o que movimenta $30 \%$ da economia da cidade (Ibge, 2015).

A cidade possui cerca de dois mil edifícios distribuídos em uma arquitetura moderna com tudo que há de mais novo e sofisticado no setor imobiliário. Balneário Camboriú é hoje uma referência para a construção civil nacional com seu alto padrão na qualidade de acabamento e design.

O mercado imobiliário de Balneário Camboriú atrai pessoas que pretendem obter melhor qualidade de vida. Diante disso, busca atender quem procura um bom lugar para viver e investir; a vinda de novos projetos como é o caso da construção do Centro de Eventos estima um crescimento significativo para os próximos anos.

O novo equipamento turístico já está sendo construído as margens da BR 101, no terreno que era pertencente a Santa Catarina Turismo (Santur). A primeira fase da obra será executada pela empresa Salver Construtora e Incorporadora, compreende a construção dos pavimentos térreo e superior alem de áreas de urbanização e estacionamento no total de $33.582,54 \mathrm{~m}^{2}$ de área construída. Além do bloco central com salas de conferências, praça de alimentação e acesso ao zoológico do Parque da Santur, o projeto arquitetônico prevê estrutura para vinte e oito salas modulares, com capacidade para até três mil pessoas (Sinduscon, 2015). A figura 1 apresenta a Projeto Arquitetônico do Centro de Eventos. 


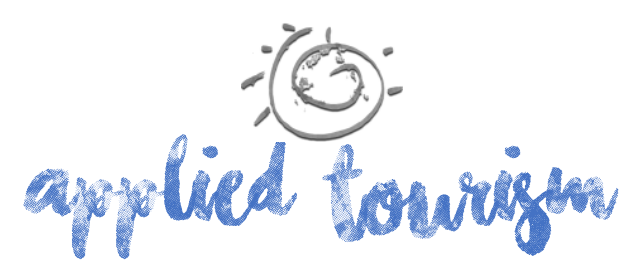

Volume 2, número 2, 2017, p. 161-179

Figura 01 - Projeto Arquitetônico do Centro de Eventos

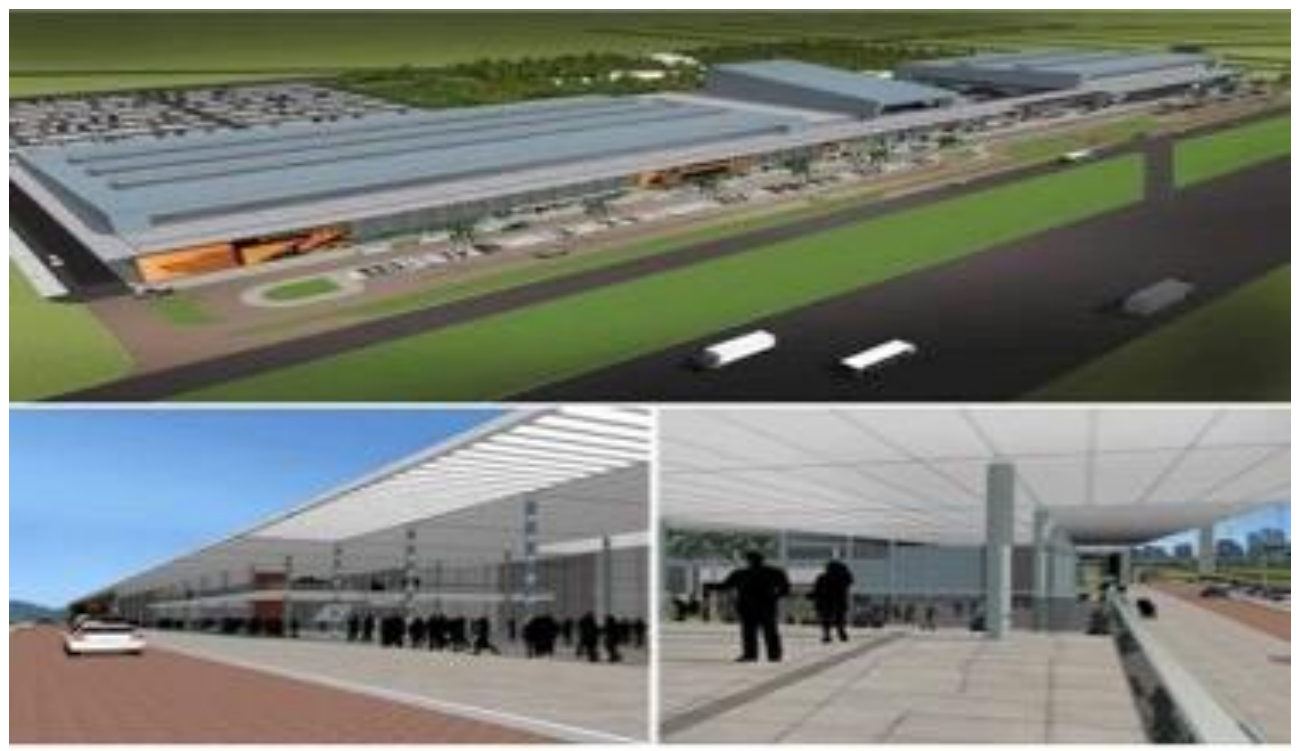

Fonte: Prefeitura Municipal de Balneário Camboriú, 2015

O investimento já vem surtindo efeito em diversos setores, seja público ou privado,

influenciando diretamente na cadeia da construção bem como na ampliação e instalação de novas fábricas, construção de shopping centers, reformas e ampliações de posto de saúdes, escolas, transporte público (acessibilidade) entre outros.

O projeto foi desenvolvido com base em princípios de sustentabilidade como máximo aproveitamento de luz natural, uso de equipamentos que reduzem o consumo de energia, uso de placas fotovoltaicas, captação de água da chuva, uso de dispositivo que reduzem o consumo de água e maximização de ventilação natural.

\section{METODOLOGIA}

Esta pesquisa foi desenvolvida na cidade de Balneário Camboriú, com abordagem qualitativa, podendo ser classificada como uma pesquisa exploratória-descritiva (Dencker, 2003), pois ao mesmo tempo em que objetiva investigar as perspectivas de representantes do setor turístico, de construção civil e imobiliário sobre a expansão e consolidação do segmento de negócios e eventos no município, procura descrever suas respostas a partir 


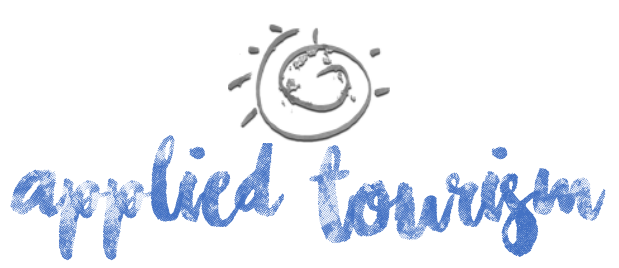

Volume 2, número 2, 2017, p. 161-179

de um formulário com perguntas fechadas em quatro rodadas de entrevista no mês de outubro/2015.

Foram escolhidos para entrevista os principais representantes dos setores envolvidos, dentre eles: o presidente do Sinduscon (Sindicato da Construção Civil - Balneário Camboriú) - Carlos Humberto M. Silva; a diretora do Balneário Camboriú Convention \& Visitors Bureau - Margot R. Libório; uma colaboradora do Setor de Planejamento da Secretaria de Turismo - Luciana Vargas; e o Ex Delegado do Creci da 11 Região, representando os corretores de imóveis locais - Milton Silveira.

Também foi realizada pesquisa com base em dados documentais e bibliográficos capazes de permitir a análise estrutural do turismo municipal e do turismo de eventos em âmbito regional, de informações sobre o segmento imobiliário de Balneário Camboriú, bem como, fatores associados à construção civil, envolvendo os temas centrais do estudo.

\section{RESULTADOS E DISCUSSÕES}

Nesta etapa serão apresentados os pontos de vista dos principais representantes dos setores de turismo, construção civil e setor imobiliário sobre a implantação do Centro de Eventos de Balneário Camboriú, finalizando com uma discussão geral. A Tabela 01 apresenta de forma resumida os principais resultados das entrevistas realizadas. 


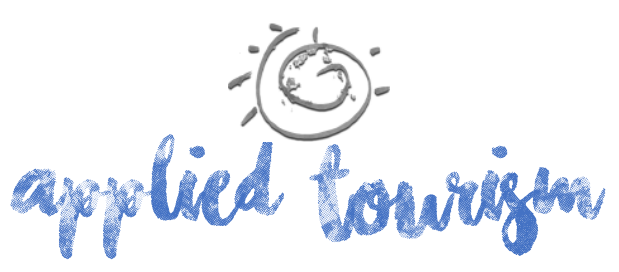

Volume 2, número 2, 2017, p. 161-179

Tabela 01 - Resultados das entrevistas

\begin{tabular}{|c|c|c|c|c|}
\hline \multirow[b]{2}{*}{ Questionário de Pesquisa } & \multicolumn{4}{|c|}{ Entrevistados } \\
\hline & $\begin{array}{c}\text { Carlos } \\
\text { Humberto }\end{array}$ & Milton Silveira & $\begin{array}{l}\text { Margot } \\
\text { Libório }\end{array}$ & Luciana Vargas \\
\hline $\begin{array}{l}\text { 1. Com relação ao seu setor } \\
\text { de trabalho, o que você } \\
\text { espera que melhore com a } \\
\text { construção do Centro de } \\
\text { Eventos de Balneário } \\
\text { Camboriú? }\end{array}$ & $\begin{array}{l}\text { Maior demanda } \\
\text { de clientes em } \\
\text { potencial para } \\
\text { aquisição de um } \\
\text { imóvel em } \\
\text { Balneário } \\
\text { Camboriú }\end{array}$ & $\begin{array}{l}\text { Espera que a } \\
\text { hotelaria } \\
\text { aumente o } \\
\text { número de leitos } \\
\text { e melhore os } \\
\text { serviços } \\
\text { prestados }\end{array}$ & $\begin{array}{l}\text { Melhoria da } \\
\text { qualidade } \\
\text { dos serviços } \\
\text { e quebra da } \\
\text { sazonalidad } \\
\text { e }\end{array}$ & $\begin{array}{l}\text { Aumento do } \\
\text { fluxo de turistas } \\
\text { no período de } \\
\text { baixa } \\
\text { temporada }\end{array}$ \\
\hline $\begin{array}{l}\text { 2. Existe algum aspecto } \\
\text { negativo que poderá } \\
\text { impactar o mercado } \\
\text { imobiliário local? }\end{array}$ & Não acredito & Não acredito & $\begin{array}{c}\text { Não } \\
\text { acredito }\end{array}$ & Não acredito \\
\hline $\begin{array}{l}\text { 3. Quanto à infraestrutura } \\
\text { urbana, qual o grau de } \\
\text { importância dos setores que } \\
\text { deverão receber } \\
\text { investimentos prioritários? }\end{array}$ & $\begin{array}{c}\text { Acesso e } \\
\text { segurança }\end{array}$ & $\begin{array}{c}\text { Acesso, } \\
\text { transporte e } \\
\text { hotelaria }\end{array}$ & $\begin{array}{c}\text { Acesso e } \\
\text { transporte }\end{array}$ & $\begin{array}{l}\text { Acesso e } \\
\text { transporte }\end{array}$ \\
\hline $\begin{array}{l}\text { 4. Com a construção civil } \\
\text { acelerada pode-se prever que } \\
\text { haverá valorização imobiliária } \\
\text { no entorno das instalações } \\
\text { do Centro de Eventos de } \\
\text { Balneário Camboriú? }\end{array}$ & $\begin{array}{l}\text { Considera como } \\
\text { uma } \\
\text { consequência } \\
\text { natural a } \\
\text { especulação } \\
\text { imobiliária } \\
\end{array}$ & $\begin{array}{l}\text { Naturalmente } \\
\text { haverá a } \\
\text { valorização ao } \\
\text { entorno e nos } \\
\text { bairros próximos }\end{array}$ & $\begin{array}{c}\text { Provavelme } \\
\text { nte haverá a } \\
\text { valorização } \\
\text { no mercado } \\
\text { imobiliário }\end{array}$ & $\begin{array}{l}\text { Auxiliará no } \\
\text { desenvolviment } \\
\text { o da periferia } \\
\text { do município }\end{array}$ \\
\hline $\begin{array}{l}\text { 5. Quais são as vantagens de } \\
\text { Investimentos em turismo de } \\
\text { eventos para Balneário } \\
\text { Camboriú? }\end{array}$ & $\begin{array}{l}\text { Fomento do } \\
\text { turismo e } \\
\text { aumento da } \\
\text { demanda } \\
\text { potencial }\end{array}$ & $\begin{array}{l}\text { Quebra da } \\
\text { sazonalidade e } \\
\text { aumento da } \\
\text { demanda de } \\
\text { potenciais } \\
\text { compradores de } \\
\text { imóveis }\end{array}$ & $\begin{array}{c}\text { Quebra da } \\
\text { sazonalidad } \\
\text { e }\end{array}$ & $\begin{array}{l}\text { Maior gasto do } \\
\text { turista de } \\
\text { eventos em } \\
\text { relação ao } \\
\text { turista de lazer, } \\
\text { trazendo } \\
\text { benefícios } \\
\text { econômicos } \\
\text { para o } \\
\text { município e a } \\
\text { diminuição da } \\
\text { sazonalidade } \\
\end{array}$ \\
\hline $\begin{array}{l}\text { 6. O turismo de eventos gera } \\
\text { empregos diretos e indiretos. } \\
\text { Como você vê essa nova } \\
\text { matriz econômica para o } \\
\text { município de Balneário } \\
\text { Camboriú? }\end{array}$ & $\begin{array}{l}\text { Não vê como } \\
\text { nova matriz } \\
\text { econômica, mas } \\
\text { como um } \\
\text { agente } \\
\text { fomentador do } \\
\text { turismo já } \\
\text { existente }\end{array}$ & $\begin{array}{l}\text { Atrativo que irá } \\
\text { trazer grande } \\
\text { desenvolvimento } \\
\text { e novas } \\
\text { oportunidades } \\
\text { para o município }\end{array}$ & $\begin{array}{c}\text { Extremame } \\
\text { nte positiva, } \\
\text { fazendo do } \\
\text { município } \\
\text { um local } \\
\text { muito mais } \\
\text { competitivo } \\
\text { para } \\
\text { captação de } \\
\text { grandes } \\
\text { eventos } \\
\end{array}$ & $\begin{array}{l}\text { Muito positiva e } \\
\text { alinhada aos } \\
\text { objetivos do } \\
\text { Plano Nacional } \\
\text { de Turismo }\end{array}$ \\
\hline
\end{tabular}

Fonte: Dados da pesquisa (2015). 


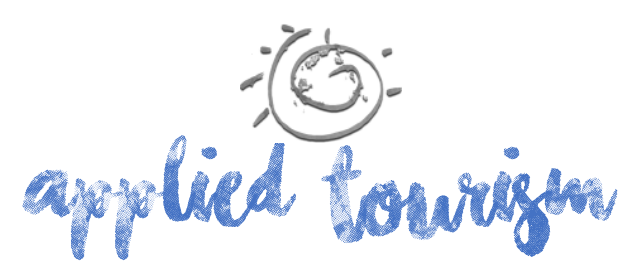

Volume 2, número 2, 2017, p. 161-179

\section{Setor de Turismo}

A entrevista realizada com a representante do Departamento de Planejamento e Pesquisas da Secretaria de Turismo de Balneário Camboriú apresentou que o setor de turismo acredita que a construção do novo Centro de Eventos poderá gerar o aumento do fluxo de turistas nos períodos de baixa temporada, melhorando a ocupação hoteleira e mantendo os empregos gerados. O setor também considera que não haverá nenhum impacto negativo no mercado imobiliário local, que pelo contrário, o município só terá a ganhar com essa iniciativa.

Quanto à infraestrutura urbana, foram enumerados como prioridades de investimento, os setores de transporte e acesso, seguidos de saúde, comércio em geral, hotelaria e por último os bares, restaurantes e similares.

No aspecto que tange a valorização imobiliária ao entorno das instalações do Centro de Eventos, o setor de turismo espera que a legislação prevista no plano diretor seja respeitada, bem como a legislação ambiental para evitar maiores problemas.

A representante do setor também enfatiza que a construção do Centro de Eventos tem como uma das principais vantagens em investimentos no turismo de eventos, pois o turista de eventos tem um gasto médio maior que o turista de lazer, trazendo benefícios econômicos para o município e outro fator importante a considerar é a captação de eventos nos períodos de baixa temporada visando diminuir a sazonalidade e auxiliando no desenvolvimento da periferia do município. O setor enxerga esta nova fonte econômica de uma forma muito positiva e alinhada aos objetivos do Plano Nacional de Turismo.

\section{Setor de Turismo de Negócios e Eventos}

A representante do setor de eventos e do turismo de negócios e eventos afirma que todo o Estado de Santa Cataria ganha com o novo Centro de Eventos "Nossa cidade é a bola da 


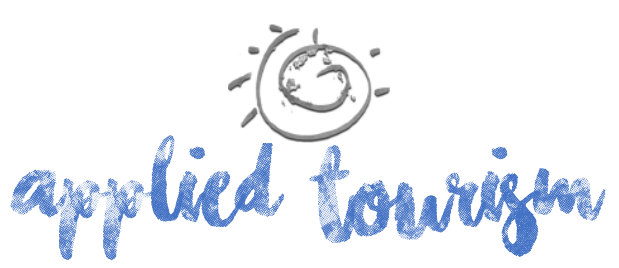

Volume 2, número 2, 2017, p. 161-179

vez", antes por não ter o espaço necessário, perdíamos grandes eventos, muitos deles para outros estados; agora estamos vendo o mercado se abrir, ressalta.

A Diretoria do Balneário Camboriú Convention \& Visitors Bureau, acredita que com a construção do Centro de Eventos deverá acontecer a quebra da sazonalidade e a melhoria na qualidade dos serviços, devido a um perfil de turista mais exigente. O setor desconhece algum aspecto negativo que possa impactar o mercado imobiliário local, pois a tendência é justamente favorecê-lo. Quanto à infraestrutura urbana, é apontado que a prioridade de investimentos deve estar relacionada inicialmente ao acesso e transporte, seguidos da saúde e não considera relevante o investimento no setor hoteleiro e de bares e restaurantes, já que a iniciativa privada pode suprir essa demanda enfatizando que Balneário Camboriú tem uma das maiores disponibilidades de leitos do País e um grande número de restaurantes e comércios comparado a outros grandes centros.

Para a representante do Convention \& Visitors Bureau, a valorização imobiliária ao entorno do Centro de Eventos provavelmente irá acontecer e pode ser comparada com o que ocorreu ao entorno do Porto de Itajá, uma vez que o fortalecimento ou surgimento de uma nova matriz econômica afeta toda uma região de forma natural.

O setor cita também como a principal vantagem de investimento em turismo de eventos a quebra da sazonalidade como já foi dito anteriormente: "Um destino de sol e mar, extremamente sazonal é fortalecido quando está inserido no mercado de eventos", pois é um mercado que trabalha essencialmente de março a novembro e de segunda a quinta feira.

Para o setor de turismo de negócios e eventos essa nova matriz econômica é extremamente positiva, já que um único evento pode acionar até 52 tipos de prestadores de serviços. Com o potencial hoteleiro e gastronômico já existente na cidade, Balneário Camboriú será potencialmente competitivo no mercado de captação de eventos, gerando empregos diretos e indiretos. 


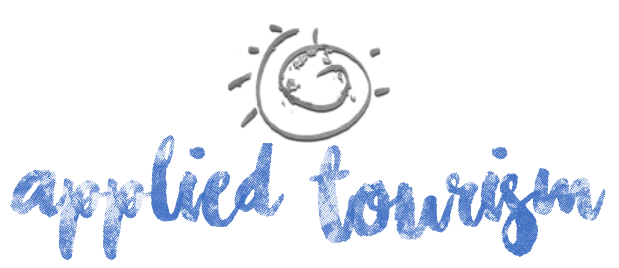

Volume 2, número 2, 2017, p. 161-179

vista pelo setor como uma nova matriz econômica, mas sim, como um fomentador da matriz principal que é o turismo.

No que se refere à infraestrutura o poder público deverá se investir prioritariamente nos acessos (mobilidade) e segurança, sendo que os demais investimentos vêm como consequência por meio da iniciativa privada como desenvolvimento local.

É preciso criar oportunidades de investimentos privados para fomentar o turismo e consecutivamente atrair investidores para o município, porém há um grande impasse na questão do poder público para que as empresas se instalem na cidade devido há falta de incentivos.

Atribuiu-se nota máxima de importância ao aspecto acesso e em seguida segurança (acessibilidade e mobilidade) como fator de influência prioritária nos investimentos do poder público.

\section{Setor Imobiliário}

O representante do setor imobiliário salienta que o turismo é a principal economia do município, e comenta sobre a importância da construção do Centro de Eventos para Balneário Camboriú, porém apresenta uma grande preocupação com o desenvolvimento da cadeia hoteleira para que a cidade possa abrigar os participantes destes grandes eventos que serão realizados.

O setor expõe que com a captação dos grandes eventos, a demanda também aumenta e a estrutura hoteleira terá que acompanhar este crescimento. Ele destaca que para atender a demanda atual do turismo de passeio e do turismo de pequenos eventos a cidade consegue alocar toda a demanda, todavia, quando o centro de eventos der início a realização dos grandes eventos, além desta demanda que são todos turistas habituais que 


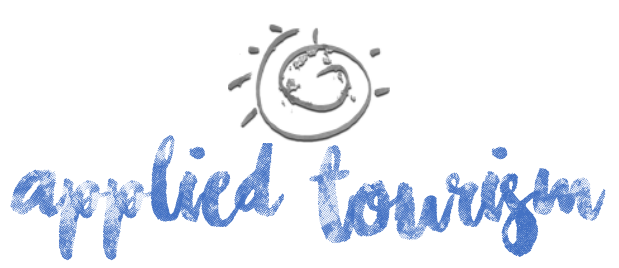

Volume 2, número 2, 2017, p. 161-179

\section{Discussão Geral}

Numa análise geral das entrevistas observa-se que todos os participantes consideram a instalação do Centro de Eventos como uma oportunidade de fomentar o turismo já existente, possibilitando a quebra da sazonalidade nos meses de baixa temporada.

Existem, no entanto, divergências no que tange aos setores que deverão ser prioritários nos investimentos da economia local e na melhoria dos serviços prestados, como é o caso da hotelaria que para Milton é insuficiente para atender esta nova demanda que irá surgir enquanto que Margot não considera um item relevante, pois acredita que investimentos da iniciativa privada podem suprir essa necessidade. Já no aspecto transporte e acesso, todos os entrevistados possuem opiniões semelhantes citando como um dos principais pontos a serem melhorados na infraestrutura da cidade.

No que se refere a uma nova matriz econômica para o município Carlos Humberto diverge dos demais entrevistados quando relata que não se trata de uma nova matriz econômica, mas sim de um agente fomentador da matriz de turismo já existente, enquanto os demais acreditam ser uma nova geradora de economia.

Além disso, todos os participantes demonstraram ter boas perspectivas quanto à implantação do Centro de Eventos, que em suas visões irá gerar empregos diretos e indiretos, aumentando a demanda de potenciais compradores de imóveis e de mais investimentos da iniciativa privada.

\section{CONSIDERAÇÕES FINAIS}

A partir das entrevistas realizadas com representantes dos setores de turismo, construção civil e imobiliário sobre a implantação do Centro de Eventos de Balneário Camboriú, é possível destacar que a capacidade de adequação do município e a organização dos setores envolvidos com o turismo de negócios e eventos complementarão toda a demanda do turismo de praia e lazer já existente. A proposta é dotar o espaço, que está 


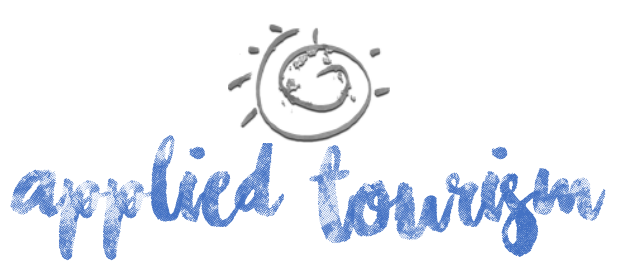

Volume 2, número 2, 2017, p. 161-179

sendo construído, de toda a infraestrutura necessária para que sejam realizados eventos de grande porte, além da inclusão de outros atrativos voltados ao entretenimento, compras, alimentação, entre outros.

Nesse sentido, a consciência do trade, dos políticos e dos administradores atuais mostrase de suma importância para acrescentar inovações e planejamentos futuros com a preocupação de manter o fluxo de eventos, a qualidade das instalações oferecidas e a infraestrutura dos bairros próximos e do município como um todo.

Dentre os resultados pôde-se identificar o aumento dos investimentos no ramo imobiliário local em decorrência da construção do Centro de Eventos, sendo considerada para muitos como uma nova matriz econômica e também que os setores de transporte e acesso precisarão de investimentos por parte do poder público a fim de mitigar as deficiências existentes, que com o aumento do fluxo de turistas precisará de uma maior atenção.

Em resumo, constata-se que Balneário Camboriú já é um destino turístico considerado competitivo, mas que com a implantação do centro de eventos poderá melhorar ainda mais sua imagem e vantagem competitiva, proporcionando aos turistas um motivo maior para visitar o local em outras épocas do ano que não sejam somente no verão a procura de sol e praias e ao morador uma oportunidade de melhoria da qualidade de vida com maiores possibilidades de emprego e renda durante todo o ano.

Por fim, destaca-se que este novo equipamento turístico poderá auxiliar o Estado de Santa Catarina e evidenciar ainda mais o turismo no município de Balneário Camboriú, posicionando-o como um dos destinos mais bem preparados para receber eventos nacionais e internacionais de grande porte no Brasil. 


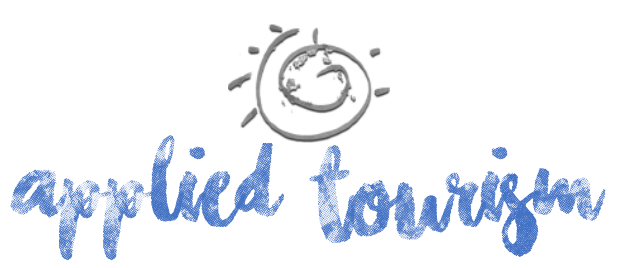

Volume 2, número 2, 2017, p. 161-179

\section{REFERÊNCIAS}

Abrasel SC. (2016). Pesquisa destaca maior presença de estrangeiros e dificuldades, como a elevação dos custos do setor. Disponível em http://sc.abrasel.com.br/component/content/article/7-noticias/505-abrasel-avaliatemporada-com-proprietarios-de-bares-e-restaurantes

Allen, J., O’Toole, W., Harris, R. \& McDonnell, I. (2011). Festival \& Special Event Management. Australia: John Wiley \& Sons.

Batista, A. V., \& Pinto, R. F. (2007). O turismo de eventos como estratégia de regeneração do mercado local. Encontro Nacional de Turismo com Base Local, 10, 89-100.

Beni, M. C. (2001). Análise estrutural do turismo. São Paulo: Editora Senac São Paulo.

Britto, J., \& Fontes, N. (2002). Estratégias para eventos: uma ótica do marketing e do turismo.

Aleph.

Canton, A. (2009). Evento: um potencializador de negócios. In: Netto, A. P., Ansarah, M. Segmentação do mercado turístico: estudos, produtos e perspectivas. Barueri, SP: Manole.

Cook, R. A., Yale, L. J., \& Marqua, J. J. (2010). Tourism: the Business of Travel (4th Ed.) Pearson Education Limited: Pearson Prentice Hall.

Cooper, C., Fletcher, J., Fyall, A., Gilbert, D. \& Wanhill, S. (2008). Tourism, Principles and practice. Essex: Pearson Prentice Hall.

Crosdales, L. D. C. C., \& Tomazzoni, E. L. (2010). Organização e gestão do evento natal luz e seus retornos para o turismo de Gramado (RS).

Coutinho, H. P. M., \& Coutinho, H. R. M. (2007). Turismo de Eventos como alternativa para o problema da sazonalidade turística. Revista Eletrônica Aboré - Publicação da Escola Superior de Artes e Turismo, v. 03.

de Luca Filho, V. (2014). A geografia das feiras de negócios em Santa Catarina: origem, evolução e dinâmica das transformações. Tese (Centro de Filosofia e Ciências Humanas - Programa de Pós-Graduação em Geografia) - Universidade Federal de Santa Catarina, Florianópolis.

Dencker, A. (2003). Métodos e técnicas de pesquisa em turismo. São Paulo: Futura.

Dias, E. (2003). Uso da criatividade para o setor de eventos. In: Bahl, M. Eventos: A importância para o turismo do terceiro milênio. São Paulo: Roca.

Donaire, D., Silva, M. P., \& Gaspar, M. A. (2009). A Rede de Negócios do Turismo: um estudo sobre suas características e implicações estratégicas. Revista Turismo Visão e Ação - Eletrônica. v. 11, n.1, p. 112-134.

Getz, D. (1997). Event management and Event tourism. New York: Cognizant Corporations.

Ibge, Instituto Brasileiro de Geografia e Estatística. (2015). Disponível em www.ibge.gov.br

Ignarra, L. R. (1999). Fundamentos do Turismo. São Paulo: Pioneira, 1999.

Rocha, E. S., Petry, T. R. E., \& Riciardi, L. P. (2017). Turismo de negócios e eventos em Balneário Bamboriú-sc: perspectivas de expansão e consolidação frente a implantação do centro de eventos do município. Applied Tourism, 2(2), 161-179. 


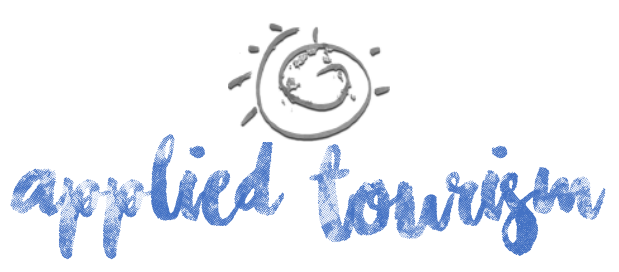

Volume 2, número 2, 2017, p. 161-179

Hoeller, E. H. (2002). Turismo de eventos: Centreventos Cau Hansen de Joinville-SC. Turismo: segmentação de mercado, 3 .

Hunt, M., \& Crompton, J. L. (2008). Investigating Attraction Compatibility in an East Texas City. International Journal of Tourism Research, 10.

Magalhães, M. D. R. A., Batista, A. V., Pinto, R. F., \& do Amaral Moretti, S. L. (2015). Análise no turismo de eventos sob a perspectiva do planejamento, estratégia e sustentabilidade. REUNIR: Revista de Administração, Contabilidade e Sustentabilidade, 1(1), 69-82.

Martin, V. (2003). Manual prático de eventos. São Paulo: Atlas.

Mtur, Ministério do Turismo através da Fipe, Fundação de Pesquisas Econômicas. (2014). Ministério do Turismo. Estudo de demanda turística. Disponível em www.turismo.gov.br

Mtur, Ministério do Turismo. (2010). Turismo de negócios e eventos: orientações básicas - 2. ed Brasília: Ministério do Turismo.

Oliveira, A. P. (2002). Turismo e desenvolvimento: planejamento e organização. Atlas.

Page, S. J. (2009). Tourism Management: Managing for Change (3rd Ed.) Elsevier: Oxford.

Sinduscon - BC, Sindicato da Indústria da Construção Civil de Balneário Camboriú. (2015). Informativo Mensal no 175 e 176 - agosto/setembro/2015.

Swarbrooke, J., \& Horner, S. (2002). O comportamento do consumidor no turismo. São Paulo: Aleph (Série Turismo).

Swarbrooke, J., \& Horner, S. (2001). Business travel and tourism. Routledge.

Tyler, D., Guerrier, Y., \& Robertson, M. (orgs.). (2001). Gestão de turismo municipal. São Paulo: Futura.

World Travel \& Tourism Council (Wttc). (2015). Travel \& Tourism: economic impact 2015 world. Disponível em http:/www.wttc.org//media/files/reports/economic\%20impact\%20research/regional\%202015/world2015.pdf

World Travel \& Tourism Council (Wttc). (2015b). Travel \& Tourism: economic impact 2015 Brazil. Disponível em https://www.wttc.org//media/files/reports/economic\%20impact\%20research/countries\%202015/brazil2015.pdf 